\title{
Effects of Smoking on Interdigestive Gastrointestinal Motility
}

\author{
W. MICHAEL McDONNELL, MD and CHUNG OWYANG, MD
}

\begin{abstract}
The effect of smoking on interdigestive gastrointestinal motility is little studied but may play a role in gastrointestinal morbidity. We studied gastroduodenal motility in 10 volunteers (five smokers and five nonsmokers) using a water-perfused pressure catheter. $\mathrm{A} \mathrm{pH}$ probe was placed in the duodenal bulb. Baseline motility was recorded until phase III of the migrating motor complex had occurred in the stomach three times in order to record two complete cycles of MMC activity. Subjects then began smoking until phase III activity occurred again (mean duration of smoking $117 \mathrm{~min}$ ). During the control period, all subjects had normal MMC cycles and there were no differences between smokers and nonsmokers. While smoking, no gastric phase III was observed in any subject and gastric motility was markedly reduced. In seven of 10 subjects, smoking did not prevent the occurrence of normal duodenal phase III activity. Three subjects had no duodenal phase III activity during smoking. The duodenal $\mathrm{pH}$ profile did not change during smoking and motilin levels continued to fluctuate in conjunction with phase III activity. In conclusion, smoking abolished phase III activity in the stomach without affecting the plasma motilin cyclic fluctuations or duodenal bulb $\mathrm{pH}$. In contrast, smoking has little effect on duodenal motility.
\end{abstract}

KEY WORDS: interdigestive migrating motor complex; motilin; duodenal pH: gastric motility; smoking: lobacco; nicotine.

Gastrointestinal complications associated with smoking are well described and include increased incidence of peptic ulcer disease, increased rate of recurrence of peptic ulcers, decreased response to treatment of ulcers with $\mathrm{H}_{2}$-receptor blockers, and increased incidence of serious complications from peptic ulcer disease (1-5). The reasons for increased gastrointestinal morbidity from smoking are unclear. Numerous studies investigating acid output, gastric blood flow, prostaglandin production, duodenal $\mathrm{pH}$, and other parameters have been inconclusive $(6,7)$. Recently increased duodenogastric reflux secondary to gastric hypomotility has been proposed to play a

\footnotetext{
Manuscript received May 4. 1995: accepted July 17, 1995.

From the Division of Gastroenterology, Department of Internal Medicine. University of Michigan School of Medicine and The Ann Arbor Veterans Aftairs Medical Center, Ann Arbor MI 481(19. Address for reprint requests: Dr. W. Michael McDonnell, $111 \mathrm{D}$. Gastroenterology Section, V.A. Medical Center, 2215 Fuller Road. Ann Arbor, Michigan 48105.
}

role in the pathogenesis of gastric ulcer $(8,9)$. It is conceivable that smoking may inhibit gastric motility, which in turn promotes duodenogastric reflux and/or delays gastric emptying of acid. However, the effects of smoking on fasting gastrointestinal motility are little studied.

Fasting motility is characterized by the interdigestive migrating motor complex (MMC). The MMC cycles during the fasting state and culminates in a wave of intense phasic contractions lasting about 5 min (phase III) which begin in the antrum and proceed through the small intestine. This is followed by a period of quiescence with little or no contractile activity (phase I) lasting about $15-60 \mathrm{~min}$ and then by a period of intermittent and irregular contractions (phase II) lasting another $15-60 \mathrm{~min}$. Phase II leads into another phase III contractile wave and the cycle is completed. Phase III of the MMC has been referred to as the "housekeeper" of the gastrointestinal 
tract, as these powerful contractions not only play an important role in gastric emptying of indigestible solids but also enhance gastric emptying of secretions including gastric acid (10). We hypothesize that smoking inhibits interdigestive MMC activity and induces a hypomotility state. To test this hypothesis, we performed studies on volunteers, both smokers and nonsmokers, during control and smoking periods in the fasting state to determine the acute effects of smoking on gastroduodenal motility and duodenal $\mathrm{pH}$.

\section{MATERIALS AND METHODS}

Subjects. Ten volunteers, five smokers and five nonsmokers. between the ages of 18 and 33 years (mean 25.8 years \pm 1.5 SEM) were recruited. There were four women and six men, and all were in excellent health. These studies were approved by the University of Michigan Institutional Review Board and informed consent was obtained from all subjects.

Equipment. Gastrointestinal motor activity was measured by a sensitive water perfusion system consisting of a pneumohydraulic capillary infusion pump that perfuses a polyvinyl catheter at $0.25 \mathrm{ml} / \mathrm{min}$ (Arndorfer Medical Spec., Inc., Racine, Wisconsin). The catheter had eight circumferential lumens with two duodenal ports 6 and $18 \mathrm{~cm}$ from the end and six gastric ports $30-35 \mathrm{~cm}$ from the end. The catheter was connected through external transducers (model P23XL, Gould Inc, Oxnard, California) to a Gould pen recorder (Instruments Div., Gould Inc., Cleveland, Ohio). A pH probe was attached to the perfusion catheter $3 \mathrm{~cm}$ distal to the last gastric pressure port for eventual placement in the duodenal bulb. The $150-\mathrm{cm} \mathrm{pH}$ probe was connected to a pH meter (Radiometer Copenhagen PHM G2) and a continuous reading was recorded on the Gould pen recorder (Figure 1).

Study Design. After an overnight fast gastrointestinal intubation was performed under fluoroscopic control. The two distal ports were located in the mid-duodenum and near the ligament of Treitz. The proximal six ports were spread across the antrum, and the $\mathrm{pH}$ probe was placed in the duodenal bulb (Figure 1). Subjects were then brought to the Clinical Research Center at the University of Michigan and placed in a bed with the head elevated $30-45^{\circ}$ for observation. A heparin lock was placed using a 20 -gauge butterfly needle for obtaining peripheral blood samples. Smokers did not smoke for $18 \mathrm{hr}$ before the study period. Subjects were then observed for the first phase III of the MMC in the gastric antrum. Phase III is identified by an intense burst of regular rhythmic contractions at a rate corresponding to the underlying slow-wave activity of the gut ( 3 contractions per minute in the antrum and 11-12 contractions per minute in the duodenum) lasting 3-10 $\mathrm{min}$ (Figure 2). This is followed by a period of quiescence, which is the hallmark phase I of the MMC. The first MMC phase III was considered the beginning of the study period. Subjects were then observed through two more phase III MMCs, thus having recorded two complete control MMC cycles. At the end of the third MMC phase III subjects

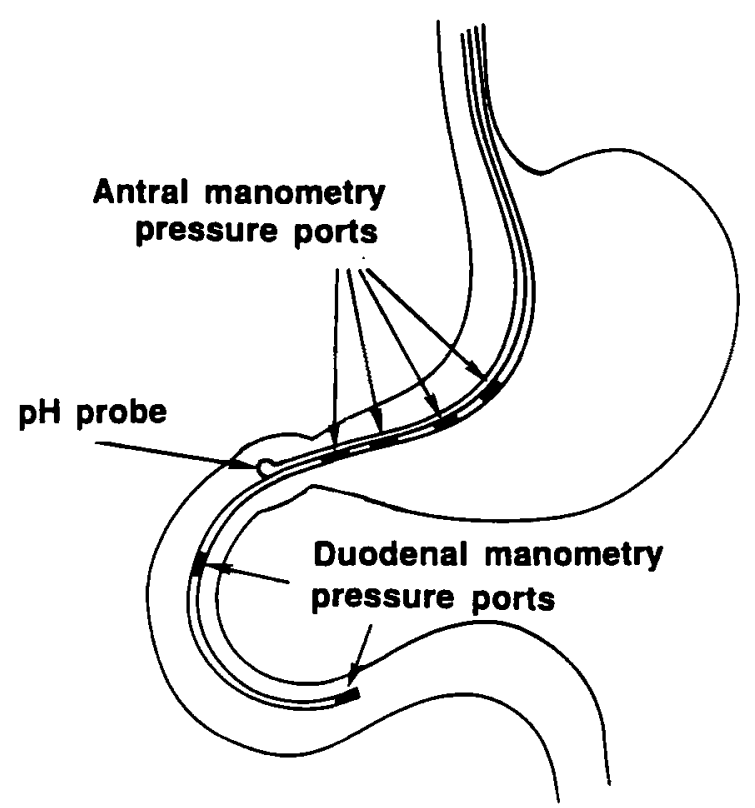

Fig 1. Gastroduodenal motility tube with $\mathrm{pH}$ probe attached distal to the last gastric port in the stomach and small intestine.

began smoking. Smokers smoked a standard 1.2-mg nicotine cigarette (Phillip Morris, Richmond, Virginia) continuously for this portion of the study. They were instructed to smoke at their usual rate. Nonsmokers smoked a standard cigar (Consolidated Cigar Co., Ft. Lauderdale, Florida) continuously. They were instructed to smoke slowly and simply draw smoke into their mouth and blow it out. This continued until the next MMC phase III and then the study was terminated or, if a phase III MMC did not occur at the expected time, the study was continued as long as the subject was able to tolerate the experiment. Cigars were used for nonsmokers because a nonsmoker without smoking tolerance could not be expected to inhale a cigarette. Cigarette tobacco is flu cured and acidic. The nicotine is ionized and therefore not well absorbed by buccal mucosa (11). Cigar tobacco is air cured and alkaline. The nicotine is ionized and readily absorbed by the buccal mucosa (11). Therefore, in a nonsmoker, a comparable smoking effect can be achieved by using a cigar rather than a cigarette Blood was drawn every 15 min throughout the study period.

Motilin. Plasma was immediately separated and stored at $-70^{\circ} \mathrm{C}$ until time of assay. Plasma motilin was measured with a radioimmunoassay by the Michigan Diabetes Research Unit as previously described (12).

Motility Measurements. Although the polyvinyl catheter we used had six lumens in the stomach, we used only the four most distal ports since we were interested in antral activity. In interpreting results, we picked a single antral tracing because all antral tracings provided similar information. Motility was initially assessed qualitatively for the presence of phase I, phase II, and phase III activity. The time of each cycle was measured in minutes from the beginning of phase III activity to the beginning of the next phase III. The motility index (MI) was determined by measuring the area under the curve on the paper tracing 


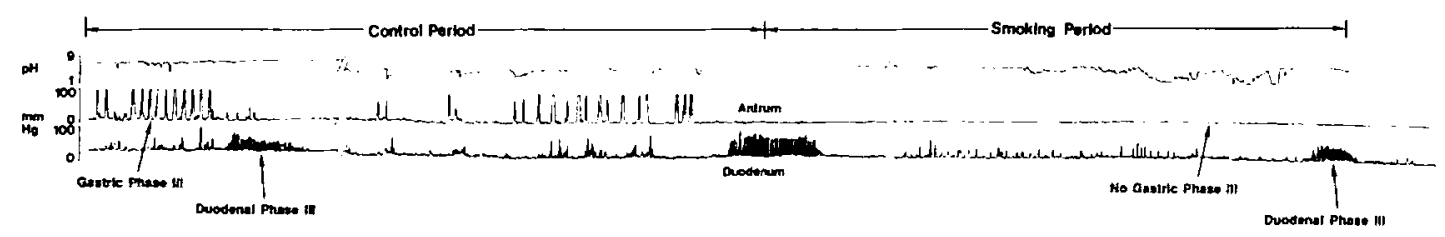

Fig 2. Tracings of $\mathrm{pH}$, gastric manometry, and duodenal manometry during control cycle and smoking cycle for one volunteer.

using a personal computer (IBM. Armonk, New York) and digitizer board (Summagraphics. Fairfield, Connecticut). Gastric MI represents the notor activity observed for the entire MMC cycle and does not distinguish between gastric phase II and phase III activity. Gastric motility data are expressed as $\mathrm{MI} / \mathrm{min} \times 100$. The duodenal MI represents only the activity seen during phase III of the MMC.

Duodenal pH. Duodenal $\mathrm{pH}$ was monitored during the entire study period to determine if the duodenal bulb was more acidic during the smoking period. Accurate position of the $\mathrm{pH}$ probe was ensured by securing the probe $3 \mathrm{~cm}$ beyond the last gastric pressure port. If the $\mathrm{pH}$ probe migrated distally, the last gastric port readings would identify its location in the pylorus or duodenum. and if the $\mathrm{pH}$ probe migrated proximally. the $\mathrm{pH}$ would drop to a continuous $\mathrm{pH} 1-2$ reading.

Statistical Methods. Data were averaged and expressed as \pm SEM. Control and smoking period data were compared using the paired and unpaired $t$ test. [Only one intervention was performed (smoking) so analysis of variance was not required]. Since multiple measurements were made in this study, the issue of simultaneous inference was addressed using the Bonferroni correction approach (13). One variable measured may be dependent on another measured variable; therefore, the significance of that variable would depend on the significance of the other variable. The Bonferroni method states that to reach a significance of $P=$ 0.05 . the individual variable measured must be significant at 0.05 divided by the number of variables measured. Five variables were measured in this study (gastric motility, duodenal motility, cycle length, duodenal $\mathrm{pH}$, and serum motilin), which means a $P$ value of 0.01 would be required to reach statistical significance.

\section{RESULTS}

Motor Activity. All subjects had normal interdigestive MMC activity (normal phase I, II and III wave morphology and periodicity) during the control period. In the control period each subject was followed through two interdigestive MMC cycles (with one exception) by observing three phase III contraction waves. All phase III contractions began in the stomach with normal aboral progression to the duodenum. Smoking produced a dramatic drop in gastric motor activity throughout the cycle, and no subject had gastric phase III activity while smoking (Figure 2). Two subjects did not have a single gastric contraction while smoking (Figure 3 ). In seven subjects the end of the cycle was heralded by the abrupt onset of duode- nal phase III contractions (Figure 2). Three subjects were observed for 130,150 , and 317 min while smoking and did not demonstrate any duodenal phase III activity. During the smoking period an average of 2.2 \pm 0.2 cigars and $9.4 \pm 1.4$ cigarettes were consumed. Each volunteer had a dramatic decrease in gastric motor activity while smoking (Figure 3 ). There was no significant difference in gastric motility between smokers and nonsmokers; therefore the data presented in Figure 4 combine both groups. The average gastric $\mathrm{MI} / \mathrm{m}$ during the control period was $33.6 \pm 2.8$ $\mathrm{cm}^{2}$ and while smoking it dropped to $4.2 \pm 1.4 \mathrm{~cm}^{2}(P$ $<0.001$ ) (Figure 4 ). The mean cycle time was $97.1 \pm$ $6.4 \mathrm{~min}$ during the control period, which was not significantly different than the $\mathrm{MMC}$ cycle length in the seven volunteers who had a duodenal phase III while smoking $(82 \pm 8.1 \mathrm{~min})$. Duodenal motor activity observed while smoking was not significantly different than during the control period (Figure 4). The mean duodenal phase III MI was $14.7 \pm 1.2$ during the first control period, $11.8 \pm 1.2$ during the second control period, and $11.6 \pm 1.2$ during the smoking period.

Duodenal pH. Typical $\mathrm{pH}$ readings were seen during the control and smoking periods in all subjects, ie, the $\mathrm{pH}$ was very stable during phase $\mathrm{I}$, always remaining between 7 and 8 , and during phase II, the baseline becoming erratic with the $\mathrm{pH}$ dropping as low as 2 on occasion (see Figure 2). The occurrence of phase III was usually accompanied by stabilization of the duo-

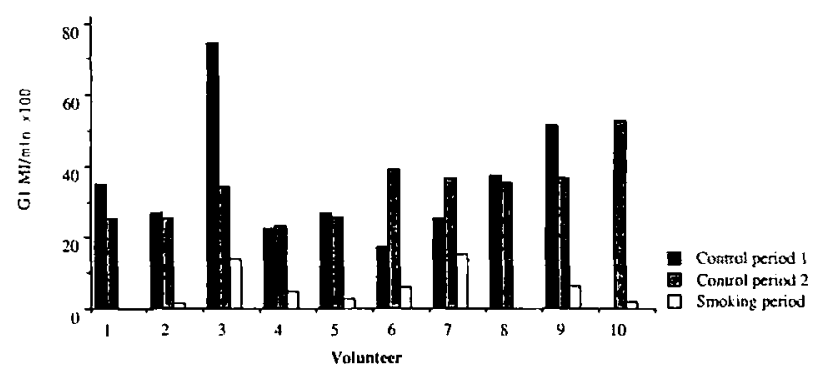

Fig 3. Gastric motility index per minute $(\mathrm{MI} / \mathrm{min} \times 1(00)$ of volunteers for each control period and smoking period. Control period 1 and 2 refer to the first and second interdigestive MMC cycle observed prior to the smoking period. The first five volunteers are nonsmokers. 


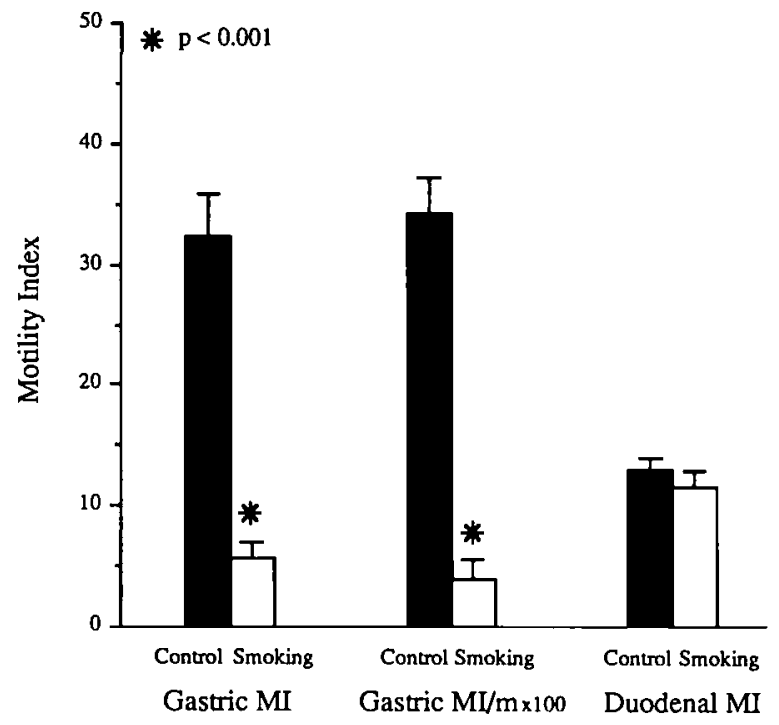

Fig 4. Gastroduodenal motility during control $[N=19$ since two complete MMCs were observed (except volunteer 10)] and smoking periods $(N=10)$. Gastric motility expressed as MI (ie, gastric MI per MMC cycle) or $\mathrm{MI} /$ minute $\times 100$ shows a marked decrease in motor activity during the smoking period $(P<0.001)$. Duodenal $M I$ in the seven volunteers who had a duodenal MMC phase III were not different than duodenal MI in the control period.

denal $\mathrm{pH}$ at around 7 . These data were quantitated by determining the percentage of time the $\mathrm{pH}$ was lower than 4.0 during the cycle period and comparing control cycles with smoking cycles. $\mathrm{pH}$ tracings were complete for four smokers and four nonsmokers. The $\mathrm{pH}$ was less than 4.0 an average of $13 \pm 6.4 \%$ of the cycle time during the control period and $9.2 \pm 2.1 \%$ of the time during the smoking period. There were no significant differences between these values, nor were there any statistical differences between smokers and nonsmokers during the control or smoking periods.

Plasma Motilin. Motilin values were available for nine volunteers, including six of the seven volunteers whose study ended in a duodenal MMC phase III while smoking. All volunteers had normal peaks of motilin just prior to phase III activity and troughs during phase I (Figure 5). To quantitate these data, the trough during phase I was compared to the peak within $10 \mathrm{~min}$ of the following phase III (Figure 6). The average trough motilin value during phase I was $165 \pm 20 \mathrm{pg} / \mathrm{ml}$ for the control period and $169 \pm 33$ $\mathrm{pg} / \mathrm{ml}$ during the smoking period (Figure 6). The average peak motilin value just prior to phase III was $275 \pm 35 \mathrm{pg} / \mathrm{ml}$ during the control period $(N=11)$ and $261 \pm 42 \mathrm{pg} / \mathrm{ml}$ during the smoking period $(N=$ 6 ). The percentage increase in motilin from phase I to phase III ranged from 26 to $155 \%$ with a mean of 76 $\pm 13 \%$ during the control period and a mean of $60 \pm$

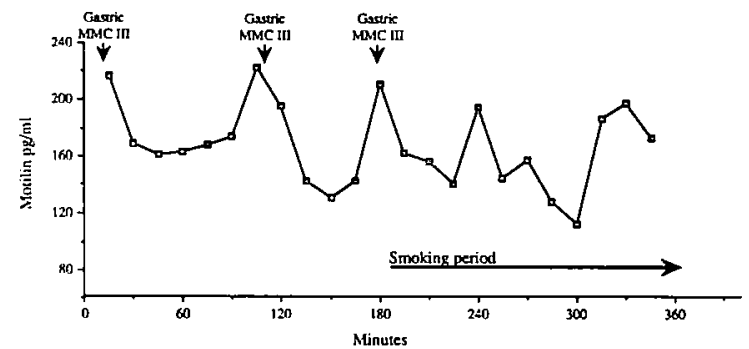

Fig 5. Serum motilin values for one volunteer throughout the study period. Note that motilin peaks around the time of each MMC phase III and troughs soon afterwards.

$11 \%$ during the smoking period. There was no difference in the percentage increase in motilin between the control and smoking phase using either the paired $(P=0.40)$ or unpaired $t$ test $(P=0.43)$.

\section{DISCUSSION}

The study design employed has the advantage of doing the control period and the smoking period on the same day during the same intubation. This eliminates variables that could arise by doing the test on different days and affect motility patterns, such as trauma during intubation, emotional state at the time of the test, mild viral illness, and other poorly under-

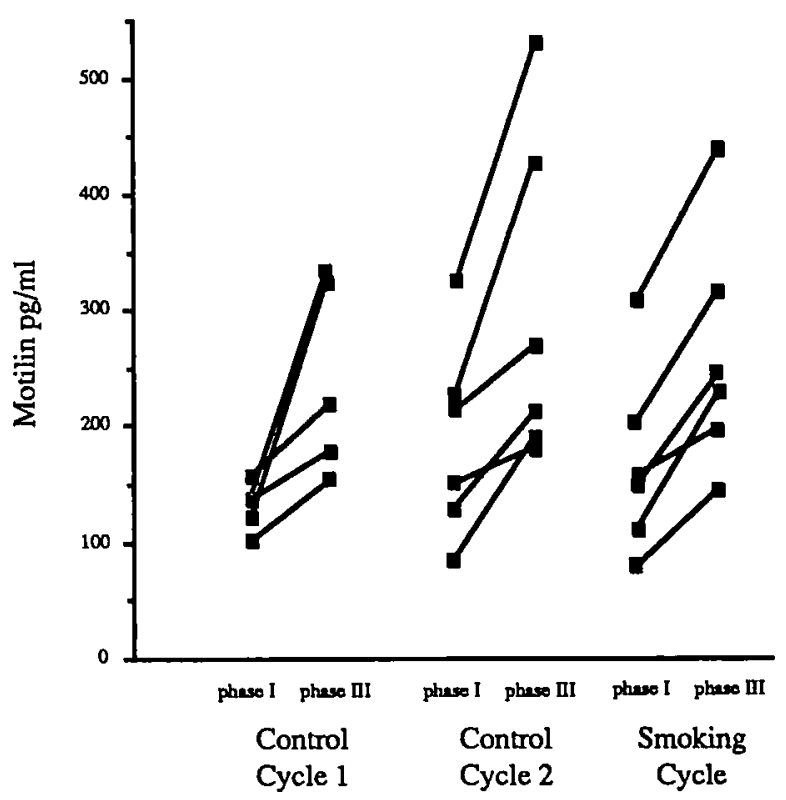

Fig 6. Serum motilin values for six of seven subjects who had a duodenal MMC phase III while smoking. Serum motilin values measured during MMC phase I are compared with peak motilin values measured within $10 \mathrm{~min}$ of MMC phase III. An increase in serum motilin from MMC phase I to MMC III is seen for each cycle of each person (paired $t ; P<0.001$ for control cycle and $P=$ 0.001 for smoking cycle). 
stood variables that effect motility. A potential problem in our study design is that the smoking portion is always done after the control portion of the exam. In our experience, motility after tubal intubation is erratic but after a period of observation typical patterns return, and we have not observed that erratic motility patterns occur after long periods of intubation. While testing order could be a confounding factor in our results, it should be noted that the smoking cycle for each person is compared with two control cycles and the differences are marked.

Our results demonstrate that in the interdigestive state smoking eliminates gastric MMC phase III activity and markedly suppresses gastric motor activity throughout the cycle. The effect on duodenal activity was not as straightforward. In seven subjects no differences in motility index or MMC cycle length were observed. However, three subjects who smoked for 130,150 , and $317 \mathrm{~min}$ had no duodenal phase III activity while smoking. The study was stopped in each of these cases because the total time the subject had volunteered was greater than $7 \mathrm{hr}$ and they were unwilling to participate further. It could be said that this period of observation was not long enough and observation for a longer time may have shown gastric or duodenal MMC activity. In any case, it appears that the inhibitory effect of smoking was much more pronounced on gastric than on duodenal phase III activity. Similarly, hyperglycemia has also been shown to inhibit gastric but not duodenal phase III activity (14). There is some experimental evidence to suggest that gastric and intestinal MMCs may be under separate control. Poitras et al (15) demonstrated the existence of motilin-independent phase III activity in their canine experiments, and Chung and Diamant (16) reported vagal blockade abolished gastric but not duodenal phase III activity. Smoking did not change the duodenal $\mathrm{pH}$ or peaks in serum motilin concentration prior to phase III activity.

There are no studies examining the effect of smoking on interdigestive motility using gastroduodenal manometric techniques. The effects of nicotine on gastrointestinal motility have been studied in dogs $(12,17)$. In the fed state intravenous nicotine inhibited gastric and duodenal activity in a dose-dependent fashion with nausea and vomiting sometimes noted at higher doses. Nicotine given during phase III interdigestive activity abolished motor activity and frequently merged the pattern into phase I. Nicotine had no stimulatory activity when given during the quiescent phase I period. Epinephrine, norepinephrine, and ganglionic stimulants including DMPP (dimethyl- phenylpiperazine) had a similar effect on gastroduodenal motility as nicotine. Reserpine, which depletes catecholamines peripherally, could block the effects of both nicotine and epinephrine. This led investigators to conclude that the inhibitory effects of nicotine in the whole animal are due to increased sympathetic tone mediated through the effects of nicotine on the sympathetic ganglia, adrenal medulla, and central nervous system rather than inhibitory effects on the parasympathetic system.

Interdigestive gastrointestinal motility is a product of myogenic slow-wave activity regulated by neural and hormonal control mechanisms (18). Motilin is one factor that has a significant role in initiating MMC phase III activity. Motilin peaks just prior to the upper gastroduodenal phase III excitation wave. Exogenous motilin infusion can initiate an ectopic phase III contraction (19), and infusion of antimotilin antibodies will inhibit phase III activity in dogs (20). In our study, motilin peaks prior to all phase III activity in the control periods and while smoking prior to the appearance of a duodenal phase III. This suggests that the effect of smoking on motility is not mediated through inhibition of motilin release but more likely is mediated through the effect of nicotine on the central and autonomic nervous system as described above in dogs.

Duodenal $\mathrm{pH}$ was studied because previous investigators have described decreased duodenal $\mathrm{pH}$ while smoking and decreased pancreatic and biliary bicarbonate secretion with tobacco or nicotine exposure, although these findings have been controversial (2125). Furthermore, duodenal bulb $\mathrm{pH}$ has a regulatory effect on interdigestive gastrointestinal motility. Acid in the duodenal bulb will inhibit gastric phase III activity, presumably preventing further duodenal acidification $(26,27)$. If smoking did cause a decrease in duodenal bulb $\mathrm{pH}$, this would be a possible cause of duodenal ulcer formation and would be a possible mechanism for changes in gastroduodenal motility. We did not see a significant drop in duodenal $\mathrm{pH}$ during the smoking period compared to the control period, indicating the inhibition of gastric motility during smoking was not due to duodenal acidification.

In summary, smoking caused a profound diminution of gastric activity and elimination of all gastric phase III activity in smokers and nonsmokers while smoking but had no effect on duodenal activity in most subjects. Neither duodenal $\mathrm{pH}$ nor serum motilin seem to mediate this effect. These changes are similar to changes in motility seen by infusion of nicotine into dogs and therefore may be mediated 


\section{SMOKING INHIBITS INTERDIGESTIVE GASTRIC MOTILITY}

through increased sympathetic tone. There was no difference in motility between smokers and nonsmokers during the control period. Future studies should be directed at the role of nicotine in gastrointestinal motility and whether modulators of sympathetic tone can alter these effects.

\section{ACKNOWLEDGMENTS}

We thank William A. Ericson, PhD, for statistical assistance. This investigation was supported in part by a Department of Veterans Affairs Associate Investigator Award (W.M.M.) and grants RO1 DK35783 (C.O.) and P30 DK34933 (C.O.) from the National Institutes of Health.

\section{REFERENCES}

1. Ross AHM, Smith MA, Anderson JR, Small WP: Late mortality after surgery for peptic ulcer. N Engl J Med 307:519-522, 1982

2. Ainley CC, Rorgacs IC, Keeling PWN, Thompson RPH: Outpatient endoscopic survey of smoking and peptic ulcer. Gut 27:648-651, 1986

3. Korman MG, Shaw RG, Hansky J, Schmidt GT, Stern AI: Influence of smoking on healing rate of duodenal ulcer in response to cimetidine of high-dose antacid. Gastroenterology 80:1451-1453. 1981

4. Hull DH, Beale PJ: Cigarette smoking and duodenal ulcer. Gut 26:1333-1337, 1985

5. Sontag S, Graham Y, Belsito A, Weiss S, Farley A, Grunt R, Cohen N, Kinnear D, Davis W, Archambault A, Achord J, Thayer W, Gillies R, Sidorov J, Sabesin S, Dyck W, Fleshler B, Cleator I, Wenger J, Opekun A: Cimetidine, cigarette smoking, and recurrence of duodenal ulcer. N Engl J Med 311:689-693 1984

6. Isenberg JI, McQuaid KR, Laine L, Rubin W: Acid-peptic disorder. In Yamada T, Alpers D, Owyang C, Powell D, Silverstein FE (eds). Textbook of Gastroenterology. Philadelphia, JB Lippincott Company, 1991, pp 1241-1339

7. Endo K, Leung FW: Effects of smoking and nicotine on the gastric mucosa: A review of clinical and experimental evidence. Gastroenterology 107:864-878, 1994

8. Miranda M, Defilippi CD, Valenzuela JE: Abnormalities of interdigestive motility complex and increased duodenogastric reflux in gastric ulcer patients. Dig Dis Sci 30:16-21, 1985

9. Read NW. Grech P: Effect of cigarette smoking on competence of the pylorus: Preliminary study. Br Med J 3(875):313316,1973

10. Oberle RL, Chen T, Lloyd C, Barnett JL, Owyang C, Meyer J, Amidon GL: The influence of the interdigestive migrating motor complex on the gastric emptying of liquids. Gastroenterology 99:1275-1282, 1990

11. Benowitz NL: Pharmacologic aspects of cigarette smoking and nicotine addiction. $\mathrm{N}$ Engl J Med 319:1318-1330, 1988

12. Carlson GM, Ruddon RW, Hug CC, Bass P: Effects of nicotine on gastric antral and duodenal contractile activity in the dog. J Pharmacol Exp Ther 172:367-376, 1970

13. Miller RG: Simultaneous Statistical Inference, 2nd ed. New York, Springer-Verlag, 1981, p 67

14. Barnett JL, Owyang C: Serum glucose concentration as a modulator of interdigestive gastric motility. Gastroenterology 94:739-744, 1988

15. Poitras P, Steinbach JH, Van Deventer G, Code CF, Walsh JH: Motilin-independent ectopic fronts of the interdigestive myoelectric complex in dogs. Am J Physiol 239:G215-G220, 1980

16. Chung SA, Diamant NE: Small intestinal motility in fasted and postprandial states: Effect of transient vagosympathetic blockade. Am J Physiol 252:G301-G308, 1987

17. Carlson GM, Ruddon RW, Hug CC, Schmiege SK, Bass $P$ Analysis of the site of nicotine action on gastric antral and duodenal contractile activity. J Pharmacol Exp Ther 172:377383,1970

18. Sarna SK: Cyclic motor activity; Migrating motor complex: 1985. Gastroenterology 89:894-913, 1985

19. Itoh Z, Takeuchi S, Aizawa I, Takayanagi R: Effect of synthetic motilin on gastric motor activity in conscious dogs. Am J Dig Dis 22:813-819, 1977

20. Lee KY, Chang TM, Chey WY: Effect of rabbit antimotilin serum on myoelectric activity and plasma motilin concentration in fasting dog. Am J Physiol 245:G547-G553, 1983

21. Konturek SJ, Solomon TE, McDreight WG, Johnson LR, Jacobson ED: Effects of nicotine on gastrointestinal secretions. Gastroenterology 60:1098-1105, 1971

22. Whitfield PF, Hobsley M: Comparison of maximal gastric secretion in smokers and non-smokers with and without duodenal ulcer. Gut 28:557-560, 1987

23. Murthy SNS, Dinoso VP Jr, Clearfield HR, Chey WY: Simultaneous measurement of basal pancreatic, gastric acid secretion, plasma gastric and secretin during smoking. Gastroenterology 73:758-761, 1977

24. Murthy SNS, Dinoso VP Jr, Clearfield HR, Chey WY: Serial $\mathrm{pH}$ changes in the duodenal bulb during smoking. Gastroenterology 75:1-4, 1978

25. Bochenek WJ, Koronzewski R: Effects of cigarette smoking on bicarbonate and volume of duodenal contents. Am J Dig Dis 18:729-733, 1973

26. Woodtli $\mathrm{W}$, Owyang $\mathrm{C}$ : Duodenal $\mathrm{pH}$ governs interdigestive motility in humans. Am J Physiol 268:G145-G152, 1995

27. Itoh Z, Aizawa I, Honda R, Takeuchi S, Mori K: Regular and irregular cycles of interdigestive contractions in the stomach. Am J Physiol 238:G85-G90, 1980 